\title{
Obstructive Uropathy: From Etiopathology to Therapy
}

\author{
Panagiotis I. Mourmouris ${ }^{\mathrm{a}, \mathrm{c}}$, Theodoros Chiras ${ }^{\mathrm{b}}$, \\ Athanasios G. Papatsoris ${ }^{\mathrm{a}}$
}

\begin{abstract}
Obstructive uropathy is an important clinical entity that both urologists and nephrologist deal with. The aim of this study is to provide the available data up to date concerning the etiopathophysiology and the possible treatment options for this emergency situation. A literature search was performed for articles in English, published in journal indexed in Medline from 1970 to 2013, using as keywords: "obstructive uropathy", "acute renal failure", "hydronephrosis", "unilateral renal obstruction" and "bilateral renal obstruction". Patients suffering from obstructive uropathy may be unaware of their problems, especially if the onset is gradual. Obstructive uropathy is responsible for a wide range of metabolic and electrolytic abnormalities that may lead to renal failure especially if the obstruction is bilateral and/or if there was a preexisting degree of renal failure. The timeframe from the occlusion of the collecting system to the development of renal impairment is shorter than we initially thought. Hopefully, nowadays there are plenty of diagnostic workouts to help urologists and nephrologists to diagnose and plan the treatment of obstructive uropathy. Obstructive uropathy needs high clinical suspicion and urgent diagnostic and therapeutic workout.
\end{abstract}

Keywords: Obstruction; Uropathy; Renal failure

\section{Introduction}

Obstructive uropathy is one of the most urgent clinical entities that both nephrologists and urologist have to diagnose [1]. Epidemiologically, obstructive uropathy accounts for $10 \%$ of the causes of acute renal failure and $4 \%$ of the cases

Manuscript accepted for publication March 24, 2014

${ }^{a}$ The 2nd Urology Department, School of Medicine, Sismanogleio General Hospital, University of Athens, Athens, Greece

${ }^{\mathrm{b}}$ Renal Unit, Sismanogleio General Hospital, Athens, Greece

${ }^{\mathrm{c}}$ Corresponding author: Panagiotis Mourmouris, Department of Urology,

School of Medicine, Sismanoglio General Hospital, University of

Athens, Athens, Greece. Email: thodoros13@yahoo.com

doi: http://dx.doi.org/10.14740/wjnu154w of chronic end stage renal failure [2]. It is classified on the basis of several criteria, including the degree, duration, site of obstruction and whether it is bilateral or not. The degree of obstruction refers to whether the obstruction of the urine flow is partial or complete. Regarding the duration of the obstruction, obstructive uropathy is categorized in acute and chronic. Acute obstruction occurs for short period of time and therefore renal parenchyma lesions are mostly reversible, while chronic obstruction, after several weeks, causes permanent damage. In cases of chronic obstruction, the term obstructive nephropathy is also used. In this review, we present the causes, pathophysiologic mechanisms, diagnostic approaches and treatment options of obstructive uropathy.

\section{Methods}

A literature search was performed for articles published in journals indexed in Medline from January 1970 to June 2013, using as keywords: "obstructive uropathy", "acute renal failure", "hydronephrosis", "unilateral renal obstruction" and "bilateral renal obstruction". Only papers written in English language were included.

\section{Results}

\section{Etiology}

The causes of obstructive uropathy can be classified into four major categories: inflammatory, neoplastic, inherited and miscellaneous (Table 1) [1]. Topographically, each of these causes can involve the kidney, ureter, bladder and urethra. Inflammatory lesions of the kidney and ureter include tuberculosis, cystic ureteritis, schistosomiasis and amyloidosis. Inflammatory diseases of the bladder and urethra include prostatitis and periurethral abscess. In obstructive uropathy due to cancer, the tumor may involve the kidney, the ureter, the bladder, the prostate and/or in the penis. Common causes of obstruction include urolithiasis, ureteropelvic junction stenosis, strictures of the ureter or urethra, benign prostatic hyperplasis and urinary tract trauma. 
Table 1. Causes of Obstructive Uropathy

\begin{tabular}{|c|c|c|}
\hline \multirow[t]{4}{*}{ Renal } & Congenital & $\begin{array}{l}\text { Polycystic kidney } \\
\text { Renal cyst } \\
\text { Peripelvic cyst } \\
\text { Ureteropelvic junction obstruction }\end{array}$ \\
\hline & Neoplastic & $\begin{array}{l}\text { Wilms tumor } \\
\text { Renal cell carcinoma } \\
\text { Transitional cell carcinoma of the collective system } \\
\text { Multiple myeloma }\end{array}$ \\
\hline & Inflammatory & $\begin{array}{l}\text { Tuberculosis } \\
\text { Echinococcus infection }\end{array}$ \\
\hline & Miscellaneous & $\begin{array}{l}\text { Stone } \\
\text { Sloughed papillae } \\
\text { Trauma } \\
\text { Renal artery aneurysm }\end{array}$ \\
\hline \multirow[t]{4}{*}{ Ureter } & Congenital & $\begin{array}{l}\text { Stricture } \\
\text { Ureterocele } \\
\text { Obstructive megaureter } \\
\text { Retrocaval ureter } \\
\text { Prune-belly syndrome }\end{array}$ \\
\hline & Neoplastic & $\begin{array}{l}\text { Primary carcinoma of ureter } \\
\text { Metastatic carcinoma }\end{array}$ \\
\hline & Inflammatory & $\begin{array}{l}\text { Tuberculosis } \\
\text { Amyloidosis } \\
\text { Schistosomiasis } \\
\text { Abscess } \\
\text { Ureteritis cystica } \\
\text { Endometriosis }\end{array}$ \\
\hline & Miscellaneous & $\begin{array}{l}\text { Retroperitoneal fibrosis } \\
\text { Pelvic lipomatosis } \\
\text { Aortic aneurysm } \\
\text { Radiation therapy } \\
\text { Lymphocele } \\
\text { Trauma } \\
\text { Urinoma } \\
\text { Pregnancy }\end{array}$ \\
\hline \multirow[t]{4}{*}{$\begin{array}{l}\text { Bladder and } \\
\text { urethra }\end{array}$} & Congenital & $\begin{array}{l}\text { Posterior urethral valve } \\
\text { Phimosis } \\
\text { Hydrocolpos }\end{array}$ \\
\hline & Neoplasmatic & $\begin{array}{l}\text { Bladder cancer } \\
\text { Prostate cancer } \\
\text { Carcinoma of urethra } \\
\text { Carcinoma of penis }\end{array}$ \\
\hline & Inflammatory & $\begin{array}{l}\text { Prostatitis } \\
\text { Paraurethral abscess }\end{array}$ \\
\hline & Miscellaneous & $\begin{array}{l}\text { Benign prostatic hypertrophy } \\
\text { Neurogenic bladder } \\
\text { Urethral stricture }\end{array}$ \\
\hline
\end{tabular}




\section{Pathophysiology}

Obstructive uropathy is usually unilateral but if it is bilateral, it may lead to anuria. In the first acute phase of obstruction (1-2 first hours), the only difference between unilateral and bilateral obstruction is between the glomerular filtration rate (GFR) and the renal blood flow (RBF) [2]. In the unilateral obstruction, the RBF is reduced in the obstructed kidney, but because of the existence of the contralateral healthy kidney, the GFR remains stable in this phase. In bilateral obstruction, GFR decreases in relevance with the degree of obstruction. The next phase is the intermediate phase ( $2-5 \mathrm{~h}$ after), followed by the late phase $(24 \mathrm{~h})$ and the phase following the first $24 \mathrm{~h}$ from obstruction. The tubular damage starts $5 \mathrm{~min}$ after obstruction due to the increasing intratubular pressure. The increased pressure is transmitted to the site of Bowman's capsule. This results in the decrease of the intravessel hydrostatic pressure and in the decrease of the GRF. Changes in the RBF further reduce the GFR. In the acute phase of obstruction, the RBF is increased, due to an increase of prostaglandins and prostacyclins caused by the compression of the vascular network of the Bowman's capsule. The increase in $\mathrm{RBF}$ is transient and after $2 \mathrm{~h}$, there is a progressive decline of up to $50 \%$. This decrease in RBF is due to the increased renal vascular resistance due to the composition of vasoconstrictor agents such as thromboxane A2 and angiotensin II. Since RBF is reduced, the pressure filtration system in the glomerulus is reduced and there is a further decline in GFR.

In patients with obstructive uropathy, changes in the function of the distal tubule are also observed, regarding the acidification and concentration process. During the acute occlusion initially there is an increase in sodium reabsorption by the tubes and the sodium concentration of the urine is $<10 \mathrm{mEq} / \mathrm{L}$, while the fraction of sodium excretion is $<$ $1 \%$ simulating prerenal acute renal failure [3]. While the obstruction is maintained, there is a significant loss of sodium mainly due to tubular damage and reduced activity of the enzyme phosphatase of triphosphate adenosine of sodiumpotassium (Na-K ATPase). The loss of the ability of the distal tubule to reabsorb sodium limits the creation of electronegative potential on the membrane of the tubules, which normally favors the elimination of hydrogen ions and potassium. The retention of hydrogen and potassium results in renal tubular acidosis, which occurs frequently in patients with obstructive uropathy. The inability of reabsorption along the loop of Henle also affects the ability of the distal nephron to condense effectively the urine. The disorder of sodium reabsorption by the carrier $\mathrm{Na}-\mathrm{K}-2 \mathrm{Cl}$ in the thick ascending Henle limb results in failure to maintain a concentration in the intermediate space in the kidney. In conjunction with the reduction of aquaporins along the entire nephron and the tubular resistance to the effects of the antidiuretic hormone, disorders in the reabsorption of water also contribute to the inability to concentrate the urine. The reduced ability of urine concentration contributes to polyuria which is observed after removal of the obstructive cause and continues until the balance of solutes has been normalized.

While obstruction remains, fibrosis, atrophy and interstitial cell apoptosis take place in the tubules [4]. This is due to the increased synthesis of metalloproteinases, which results in extracellular fibrin deposition and the activity of macrophages. Macrophages produce cytokines (for example, interleukin 2 and 6, transforming growth factor-beta1, clusterin) which contribute to inflammation and fibration [5]. Furthermore, an accumulation of fibroblasts takes place in the interstitium, which under the influence of cytokines are converted into myofibroblasts inside the extracellular matrix. A conversion of epithelial cells of the renal tubules into active fibroblasts is observed, through suppressing factors such as tubular epidermal growth factor [6]. Also, apoptosis of the epithelial cells of renal tubules leads to atrophy of the tubules. Furthermore, the stimulation of the renin-angiotensin and the action of free oxygen radicals play a role in the development of interstitial fibrosis. If obstruction is not relieved, cell death occurs within approximately 15 days. These histological lesions remain partially after the relief of the obstruction, explaining in some cases the persistence of renal insufficiency [7].

The increased intratubular pressure causes distension of the renal collecting system. Hydronephrosis involves firstly the calyces and after the pelvis. The effects in the renal parenchyma caused by atrophy are related to the increased pressure and ischemia of arcuate arteries crossing the base of the renal pyramids. As the pressure within the renal collecting system approaches the glomerular filtration pressure (6$12 \mathrm{mmHg}$ ), less urine are produced and the condensing ability of the kidney is gradually lost. The urine still produced are reabsorbed into the interstitial tissue and lymphatics (pyelointerstitial backflow). By this mechanism, an obstructed kidney can continue to produce urine.

\section{Diagnostic work-up}

Early diagnosis of the cause of obstructive uropathy is crucial for the prognosis of the disease. Ultrasonography (US) of the urinary tract, the computerized tomography (CT) and CT urography (three-dimensional image reconstitution) using intravenous contrast when renal function is good are gold standard diagnostic tests. US is usually the first imaging examination performed. However, hydronephrosis is a morphological entity and does not necessarily represent a functional disorder. Laing et al reported that when hydronephrosis was diagnosed, there was $35 \%$ false negative result in the diagnosis of acute obstructive uropathy [8]. In obstructive uropathy, Doppler US can reveal a kidney resistance index $>0.7$, and a difference in the resistance index between the two kidneys $>0.06-0.1$ [9]. The widely used intravenous urography can provide useful information about 


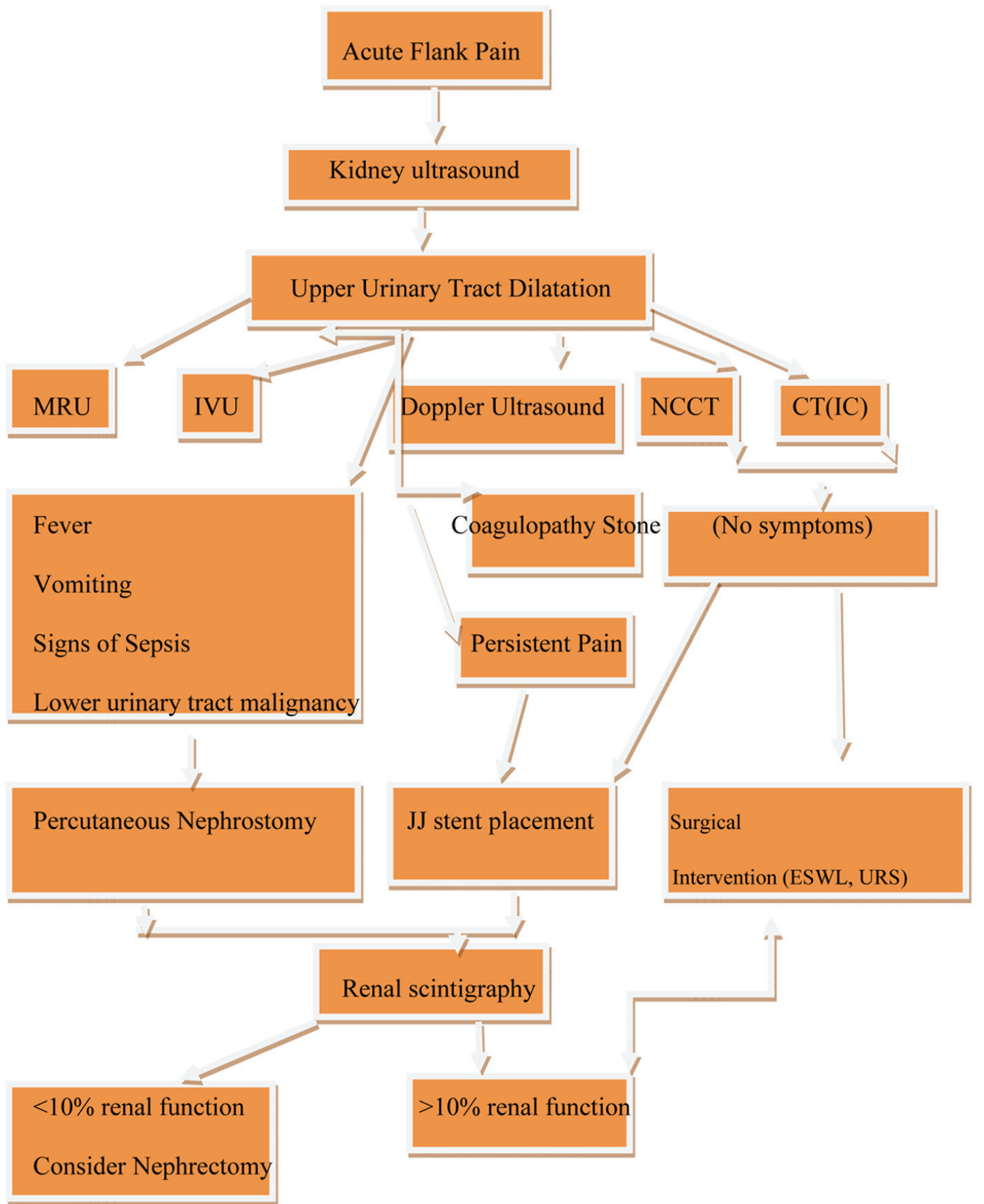

Figure 1. Diagnostic work-up and management of obstructive uropathy. IVU: intravenous urography; NCCT: non-contrast computed tomography; CT (IC): computed tomography with intravenous contrast; ESWL: extracorporeal sound wave lithotripsy; URS: ureteroscopy; MRU: magnetic resonance urography.

renal function and the level of obstruction but the use of the nephrotoxic contrast significantly limits its use in patients with impaired renal function [10]. In patients that we need to avoid exposure to ionizing radiation (for example, pregnant women) or in cases of allergy to iodized contrasts, magnetic urography can be performed [11, 12].

After the management of obstructive uropathy, radioisotopic techniques can demonstrate the residual renal function.
In renal scintigraphy, most commonly used radioisotopes are (Tc) $99 \mathrm{~m}$ DMSA, the (Tc) 99m MAG 3 and the (Tc) 99m DTPA $[13,14]$.

\section{Surgical management and follow-up}

Emergency treatment of obstructive uropathy is needed in the presence of bilateral obstruction, urosepsis, uremia and 
hyperkalemia, persistent renal colic, worsening of hydronephrosis and renal impairment (creatinine increased, or GFR decreased which is a more accurate).

Regarding the dilemma to insert a ureteral stent (JJ stent) or a percutaneous nephrostomy, literature indicates that both procedures do not show any statistically significant difference in terms of efficacy [15]. However, in some hospitals, percutaneous nephrostomy is placed only by the interventional radiologists that may not be available in an emergency basis. In patients that receive anti-coagulation medication, the preferred therapy is JJ stent placement whereas in the case of urosepsis, percutaneous nephrostomy placement is the gold standard therapy. In obstructive uropathy due to cancer, there may be difficulties during the insertion of a $\mathrm{JJ}$ stent [15].

After the management of the obstruction, polyuria may happen, especially in cases of bilateral obstruction or obstruction in a solitary kidney. Polyuria is due to a significant decrease in the receptor transport and because of reduced sodium reabsorption from the descending limb of the Henle loop. Usually, polyuria resolves when fluid and electrolyte homeostasis is achieved. Monitoring the level of consciousness and the vital signs, electrolyte supplementation and a gradual reduction of the administered intravenous fluids are essential.

\section{Pain management}

Obstructive uropathy pain is due to the increase of the pressure within the collecting system and due to ureteral wall/ renal capsule distention. Drugs are used to treat pain associated with acute renal colic, involve nonsteroidal anti-inflammatory drugs (NSAIDs), narcotic analgesics, corticosteroids and alpha blockers [16]. NSAIDs have been demonstrated to reduce collective system pressure by targeting the inflammatory basis of pain [17]. As expected the choice of pain management should be based on the patient clinical profile. In these terms, NSAIDs should not be used in patients with renal insufficiency.

\section{Prognosis and future perspectives}

It appears that patient's age, duration of obstruction, initial renal function and existence of urine extravasation are prognostic factors. Most researchers agree that obstruction remaining for more than 6 weeks results in the emergence of a degree of irreversible chronic renal disease. The US measurement of the thinning of the renal parenchyma can assess the extent of renal damage [18]. Kiratli et al reported that the presence of collagen and elastin in the renal parenchyma is also associated with negative prognosis [19]. Studies have used these molecules as prognostic factors of obstructive uropathy [20].

There are available data in the literature concerning ther- apies that are used in order to minimize kidney damage in chronic renal failure. These treatment modalities are potentially adjuvant therapies after treating obstructive uropathy. Angiotensin receptor 1 blockers (ARBs) are nephroprotective drugs in chronic kidney disease and early treatment with an ARB could preserve renal function [21]. Another study demonstrated the beneficial effects of ARBs on glomerular injury, which were contributed to the blockade of the AT1 receptor and to the increased angiotensin effects transduced through the AT2 receptor [22].

\section{Conclusions}

In obstructive uropathy, the understanding of the underlying pathophysiological changes may help to increase the clinical suspicion of both urologists and nephrologists. There are diagnostic and therapeutic work-ups (Fig. 1) that can contribute to the best management of the patients. Larger studies assessing the efficacy of such algorithms are needed as well as closer collaboration between urologists and nephrologists.

\section{Conflict of Interest}

No conflict of interest to declare.

\section{Funding}

None.

\section{References}

1. Tseng TY, Stoller ML. Obstructive uropathy. Clin Geriatr Med. 2009;25(3):437-443.

2. Siddiqui MM, McDougal WS. Urologic assessment of decreasing renal function. Med Clin North Am. 2011;95(1):161-168.

3. Robben JH, Knoers NV, Deen PM. Regulation of the vasopressin V2 receptor by vasopressin in polarized renal collecting duct cells. Mol Biol Cell. 2004;15(12):56935699.

4. Chevalier RL. Pathogenesis of renal injury in obstructive uropathy. Curr Opin Pediatr. 2006;18(2):153-160.

5. Hewitson TD. Renal tubulointersitial fibrosis: common but never simple. Am J Physiol Renal Physiol. 2009;296:1239-1244.

6. Harris KP, Klahr S, Schreiner G. Obstructive nephropathy: from mechanical disturbance to immune activation? Exp Nephrol. 1993;1(3):198-204.

7. Harris RH, Yarger WE. Renal function after release of unilateral ureteral obstruction in rats. Am J Physiol. 
1974;227(4):806-815.

8. Laing FC, Jeffrey RB, Jr., Wing VW. Ultrasound versus excretory urography in evaluating acute flank pain. Radiology. 1985;154(3):613-616.

9. Nori G, Granata A, Leonardi G, Sicurezza E, Spata C. The US color Doppler in acute renal failure. Minerva Urol Nefrol. 2004;56(4):343-352.

10. Violon D. Renal failure and iodinated contrast media. A review. JBR-BTR. 1999;82(2):57-62.

11. Jorgensen B, Keller AK, Radvanska E, Rittig S, Taagehoj-Jensen F, Frokiaer J, Jorgensen TM, et al. Reproducibility of contrast enhanced magnetic resonance renography in adolescents. J Urol. 2006;176(3):1171-1176.

12. Grattan-Smith JD, Little SB, Jones RA. MR urography evaluation of obstructive uropathy. Pediatr Radiol. 2008;38(Suppl 1):S49-69.

13. Tremel F, Caravel JP, Siche JP, Chevallier M, Mallion JM. [Diagnostic value of renal scintigraphy with MAG 3 and DTPA in the diagnosis of renal artery stenosis]. Arch Mal Coeur Vaiss. 1996;89(8):1035-1039.

14. Eskild-Jensen A, Gordon I, Piepsz A, Frokiaer J. Congenital unilateral hydronephrosis: a review of the impact of diuretic renography on clinical treatment. J Urol. 2005;173(5):1471-1476.

15. Docimo SG, Dewolf WC. High failure rate of indwelling ureteral stents in patients with extrinsic obstruction: experience at 2 institutions. J Urol. 1989;142(2 Pt 1):277-279.
16. Micali S, Grande M, Sighinolfi MC, De Carne C, De Stefani S, Bianchi G. Medical therapy of urolithiasis. J Endourol. 2006;20(11):841-847.

17. Das D, Teece S. Best evidence topic report. Intravenous NSAID's in the management of renal colic. Emerg Med J. 2006;23(3):225.

18. Feder MT, Blitstein J, Mason B, Hoenig DM. Predicting differential renal function using computerized tomography measurements of renal parenchymal area. J Urol. 2008;180(5):2110-2115.

19. Kiratli PO, Orhan D, Gedik GK, Tekgul S. Relation between radionuclide imaging and pathologic findings of ureteropelvic junction obstruction in neonatal hydronephrosis. Scand J Urol Nephrol. 2008;42(3):249-256.

20. Chevalier RL. Obstructive nephropathy: towards biomarker discovery and gene therapy. Nat Clin Pract Nephrol. 2006;2(3):157-168.

21. Alvarez-Prats A, Hernandez-Perera O, Diaz-Herrera P, Ucero AC, Anabitarte-Prieto A, Losada-Cabrera A, Ortiz A, et al. Combination therapy with an angiotensin II receptor blocker and an $\mathrm{HMG}-\mathrm{CoA}$ reductase inhibitor in experimental subtotal nephrectomy. Nephrol Dial Transplant. 2012;27(7):2720-2733.

22. Naito T, Ma LJ, Yang H, Zuo Y, Tang Y, Han JY, Kon V, et al. Angiotensin type 2 receptor actions contribute to angiotensin type 1 receptor blocker effects on kidney fibrosis. Am J Physiol Renal Physiol. 2010;298(3):F683691. 